\title{
Histopathological and Clinical Characteristics of Surgically Removed Cavernous Venous Malformations (so-called Cavernous Hemangiomas) of the Orbit
}

\author{
VICTOR VLAD COSTAN ${ }^{1}$, ANCA SAVA ${ }^{2,7 *}$, ALEXANDRU CARAULEANU3*, CLAUDIA FLORIDA COSTEA ${ }^{4,6}$, ANDREI IONUT CUCU5, \\ GABRIELA DIMITRIU ${ }^{6}$, GABRIELA FLORENTA DUMITRESCUㄱ, NICOLETA DUMITRESCUㄹ, MARIA SILVIA STOICESCU ${ }^{8}$, \\ GHEORGHE RAFTU,' MIHAELA DANA TURLIUC ${ }^{5,10}$ \\ 'University of Medicine and Pharmacy Grigore T. Popa, Department of Oral and Maxillo-Facial Surgery, 16 Universitatii Str.,700115, \\ lasi, Romania \\ 2University of Medicine and Pharmacy Grigore T. Popa, Department of Anatomy, 16 Universitatii Str.,700115, Iasi, Romania \\ 3University of Medicine and Pharmacy Grigore T. Popa, Department of Obstetrics and Gynecology, 16 Universitatii Str.,700115, \\ lasi, Romania \\ ${ }^{4}$ University of Medicine and Pharmacy Grigore T. Popa, Department of Ophthalmology, 16 Universitatii Str.,700115, Iasi, Romania \\ ${ }^{5} 2^{\text {nd }}$ Neurosurgical Clinic, Prof. Dr. Nicolae Oblu Emergency Clinical Hospital, 2 Ateneului Str.,700309, Iasi, Romania \\ ${ }^{6} 2^{\text {nd }}$ Ophthalmology Clinic, Prof. Dr. Nicolae Oblu Emergency Clinical Hospital, 2 Ateneului Str.,700309, lasi, Romania \\ 'Laboratory of Pathology, Prof. Dr. Nicolae Oblu Emergency Clinical Hospital, 2 Ateneului Str.,700309, lasi, Romania \\ ${ }^{8}$ Carol Davila University of Medicine and Pharmacy, Faculty of Medicine, Department of Obstetrics, Gynecology and Neonatology, \\ 8 Eroii Sanitari, 050474, Bucharest, Romania \\ ${ }^{9}$ Ovidius University of Medicine and Pharmacy, 124 Mamaia Blvd., 900527, Constanta, Romania \\ ${ }^{10}$ University of Medicine and Pharmacy Grigore T. Popa, Department of Neurosurgery,16 Universitatii Str., 700115, Iasi, Romania
}

\begin{abstract}
Cavernous venous malformation (CVM) is the most common primary vascular lesion of the orbit. The aim of this study is to present authors 'experience regarding fourteen patients with orbital CVM (so-called cavernous hemangioma) and identify their clinical and histopathological particular characteristics. From 2010 to 2017 a total of 14 patients were diagnosed with orbital cavernous hemangiomas and treated by the authors. Patients' socio-demographic, clinical, radiological, and surgical findings were retrospectively retrieved from medical records and analyzed. Diagnosis of a cavernous hemangioma was confirmed histologically in all cases. Results: All 14 patients were females, with a mean age of 44.2 years old, ranging from 13 years to 57 years. The left orbit was affected in eleven (78.57\%) cases. A painless, gradually progressive proptosis and visual disturbance were the main clinical signs. In four (28.57\%) cases, the lesion was incidentally discovered at imaging evaluations for persistent headache. All patients were accurately diagnosed preoperatively based on computed tomography (CT) exam or magnetic resonance imaging (MRI). The tumors were removed successfully by anterior orbitotomy. Transconjunctival approach proved to be an important surgical procedure in their treatment, with excellent results and a low risk of complications. Histologically, all lesions revealed large vascular channels with endothelium lining and multilaminar smooth muscle layers in their walls, but also nests of small capillary channels in interstitium. No intravascular thrombosis or stromal lymphocytes could be seen. Orbital cavernous hemangiomas presented clinical, imaging and histological features of a benign lesion. Having to deal with extraconal lesions, we successfully used anterior orbitotomy, mainly the transconjuctival approach, with no complications or recurrences after a six-month follow-up period. Histologically, all lesions revealed images being most closely to dysplastic veins. So, we concluded that the so-called orbital cavernous hemangioma was rather a cavernous venous malformation.
\end{abstract}

Keywords: orbit, cavernous hemangioma, cavernous venous malformation, histological examination.

Vascular neoplasms represent $4 \%$ of orbital lesions, but so-called cavernous hemangioma is the most common of them [1]. Immunohistochemical staining was the evidence for considering this lesion a malformation rather than a tumor. Osaki et al. (2013) have shown these kind of vascular lesion are characterized by a virtual absence of Ki-67 positivity [2].

This is a non-infiltrative, slowly progressive lesion, symptomatic in middle-aged patients, especially women [3], and the stimulation in their growth during pregnancy reported in studies [4- 6] seems to suggest hormonal influence. The location of most of these malformations is typically intraconal and lateral in location but rarely it can develop in extraconal areas [7-11]. Usually, this malformation is a unique lesion, but Wang and Yan described four cases of multiple cavernous hemangiomas of the orbit in their series of 214 patients with this pathology [12]. Also, Shields et al. (2000) reported a case with bilateral cavernous haemangiomas of the orbit [13].

Some reports admit that it is not possible to distinguish this lesion only on a clinical background from the rare and potentially lethal hemangiopericytoma. So, a final pathological diagnosis is required after surgical excision of an orbital vascular tumor [14].

The present study aims to present authors' clinical, imaging, pathological and treatmentexperiences regarding fourteen patients with orbital cavernous hemangiomas and to identify their particular characteristics.

*email: dr.anca.sava.68@gmail.com,Phone(+40)744303678; acarauleanu@yahoo.com, Phone (+40)0744517106. 


\section{Experimental part}

Materials and methods

Study design

During 7 years (from 2010 to 2017), a total of 14 patients with orbital cavernous hemangiomas were treated by the authors and were included for the analysis. Patients' sociodemographic, clinical, radiological, and surgical findings were retrospectively retrieved from medical records and analyzed. Diagnosis of CVM was confirmed histologically in all cases. For this study, the pathologists reviewed all histological samples.

\section{Clinical and imaging evaluation}

The ophthalmic examinations included visual acuity (VA) measurement with Snellen charts at a distance of 6 meters, motility of eyeball, pupillary reflex, proptosis measurement with Hertel exophthalmometer, Goldmann tonometry for intraocular pressure, and fundus examination with direct ophthalmoscope. The indications for surgical therapy included the presence of at least one of the following signs and symptoms: visual impairment, progressive and disfiguring unilateral proptosis, double vision and pain.

Preoperatively, 6 patients underwent MRI, 5 underwent CT and the rest of them underwent both investigations without contrast.

\section{Surgical technique and pathological analysis}

Surgical removal was performed under general anaesthesia. The mass excision used the transconjunctival approach or the transcutaneous incision.

All resected specimens were grossly described and representative samples were fixed in 10\% neutral-buffered formalin and embedded in paraffin blocks. 4-im sections were cut and stained with hematoxylin and eosin $(\mathrm{H}$ and E). In all cases the diagnosis of a CVM was confirmed. For this study, all slides were reexamined under routine light microscopy by two independent pathologists in order to identify their common histopathological characteristics. All patients were followed up at least for 6 months postoperatively.

\section{Results and discussions}

Sociodemographic data, clinical and imaging characteristics

All patients were women and their ages varied from 13 to 57 years (mean age was 44.2 years \pm 5.7 years). In the present study, the main presenting sign among these patients was proptosis in ten cases (71.42\%) (fig. 1), but seven patients (50\%) presented diplopia, too. In four cases $(28.57 \%)$, the lesion was discovered incidentally at imaging evaluations for persistent headache. The left orbit was affected in eleven cases (78.57\%) and the right orbit in three cases $(21.42 \%)$. No case was bilaterally involved.

CT images of patients included in the study revealed a round well-defined soft tissue tumor (fig. 2). At MRI the aspect of the tumor was similar to CT images, but the

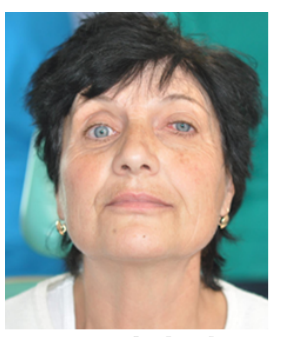

Fig. 1. Patient with displacement of the left eye opposite to the position of the tumor.

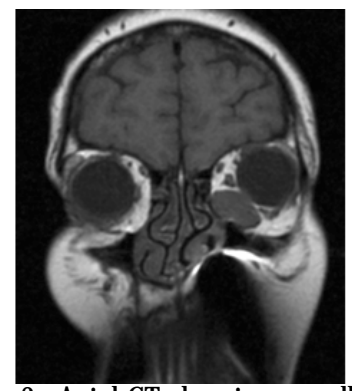

Fig. 2. Axial CT showing a welldefined ovoid lesion. signal in T1 was isointense compared to the muscle, and in T2 hyperintense compared to the muscle.

Surgical procedure and pathological findings

Our cases were located in the extraconal inferior or medial orbital compartments, so the surgical treatment was represented by anterior orbitotomy. In twelve cases $(85.71 \%)$ we performed tumor excision using the transconjunctival approach and in two cases (14.28\%) we chose the transcutaneous incision. Total tumor resection was achieved in all the cases (fig. 3).

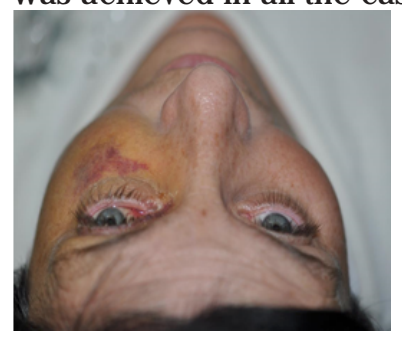

Fig. 3. Postoperative evolution following transcutaneous incision, 7 days after surgery.

Grossly, the removed lesions were well circumscribed tumors, with a reddish gray color, with soft but solid consistency. On cut surface, a sponge-like aspect could be seen. Microscopically, common to our cases was the presence of a fibrous pseudo-capsule that encapsulated each of the resected tumors (fig. 4A, 5B, 6A). Every lesion was composed of large irregular vascular channels filled with blood and lined by endothelial cells. These vascular channels were tightly knit, but separated by fibrous interstitium in various quantities (fig. 4B, 5A, 6A). Almost all vascular spaces from every analyzed lesion had multilaminar smooth muscle walls with various thicknesses, ranging from one to ten layers for the same blood vessel (fig. 5B, 6A, 6B). All cases showed buddingoff of capillary channels from cavernous spaces into the interstitium (fig. 5C, 5D, 6A). No intravascular thrombosis or stromal lymphocytes could be seen.

Six months after surgery, the exophthalmos decreased, the vision improved and there was no recurrence of the lesions at the last follow-up.

In the last years, some reports introduced a new nomenclature for orbital cavernous hemangioma as they labelled it as cavernous venous malformation (CVM) [15]. This entity usually occurs rarely in children but frequently in adult patients with ages between 40 to 60 years and it has a female predominance $(60-70 \%)[15,16]$. Our cases proved to be all females, with a mean age comparable with other studies [17-19].

A possible explanation for sex predilection has recently been proposed. According to Jayaram et al. (2015), in postmenopausal women previously diagnosed with orbital cavernous hemangioma, the lesions either remained
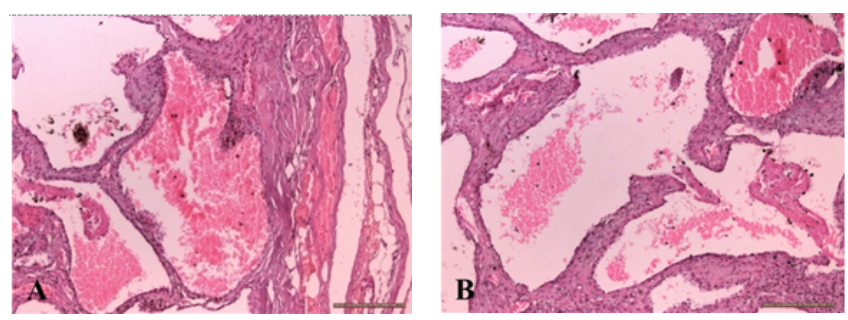

Fig. 4. Histopathological images of orbital cavernous venous malformation: Case 1. A). Large cavernous vascular channels filled with blood and lined by a single layer of flattened endothelial cells

and separated by scant connective tissue stroma. A fibrous pseudocapsule surrounded the lesion ( $H$ and $E$ staining, x10) B). The central part of the lesion showed large, endothelium-lined, blood-filled spaces, which are tightly knit and separated by thick septa ( $\mathrm{H}$ and $\mathrm{E}$ staining, $\mathrm{x} 10$ ). 

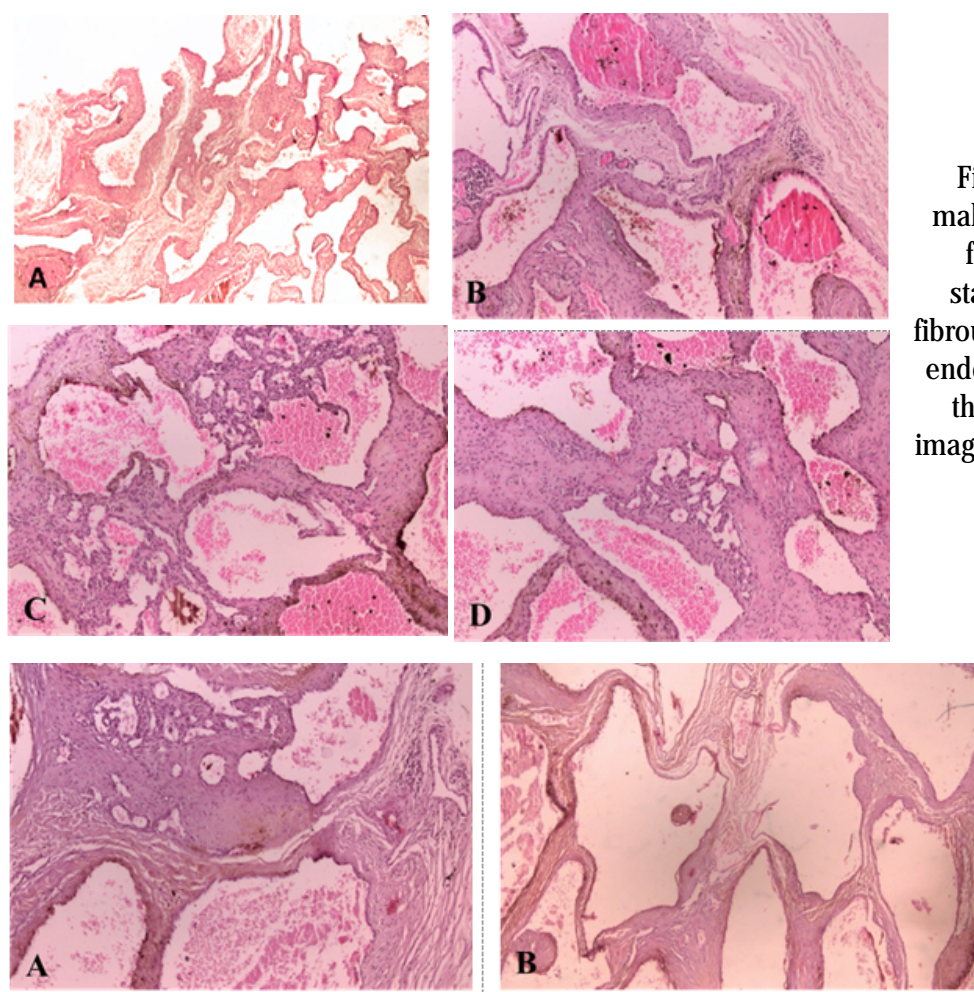

Fig. 5. Histopathological images of orbital cavernous venous malformation: Case 2. A). Large, anastomosing vascular spaces,

filled with blood and separated by fibrous stroma ( $\mathrm{H}$ and $\mathrm{E}$ staining, x5). B). Well-circumscribed lesion surrounded by a fibrous pseudocapsule and made of large vascular spaces lined by endothelium and multilaminar smooth muscle walls with various thicknesses ( $\mathrm{H}$ and $\mathrm{E}$ staining, $\mathrm{x} 10$ ). C) and D). Microscopical images of budding-off of capillary channels from cavernous spaces into the interstitium ( $H$ and $E$ staining, $x 10)$. stable or decreased in size, suggesting that female sex hormones could be involved in the lesion progression [20].

Cavernous hemangioma is usually solitary and unilateral, most commonly involving the leftorbit [21]. Our study confirms this predominance of involvement.

In rare cases, this vascular lesion may be associated with other vascular malformations or with Maffucci syndrome (consisting in multiple enchondromas and soft tissue hemangiomas) or blue rubber bleb nevus syndrome (defined by bluish cutaneous and mucosal hemangiomas, enteric hemangiomas, and gastrointestinal bleeding) [22, 23].

The most frequent location is the retrobulbar compartment of the orbit, especially the lateral aspect [16, 21]. The most common sign and symptom is exophthalmos, which is present in 70-95\% of cases [2426]. At initial presentation, the average value of proptosis is approximately $5 \mathrm{~mm}$ and its progression is calculated to be about $2 \mathrm{~mm}$ per year [27]. When the cavernous hemangioma is located intraconally, it can lead to a progressive axial proptosis. When it is located in the extraconal orbital space, the displacement of the globe is opposite the position of the tumor (fig. 1). Another common symptom is impairment of visual acuity (50\%), which appears when the hemangioma compresses the optic nerve. Also, local pain, visual field defects, diplopia, and chronic headache can appear in less than $20 \%$ of cases [24]. Similar to other studies, we encountered exophthalmos in almost three quarters of our cases, all females, but we found a higher rate of diplopia, probably due to the small sample size.

A palpable mass is rarely present in cases with cavernous hemangiomas and optic atrophy is also noted occasionally. When the tumor is located in the vicinity of the globe, it may induce hyperopia and choroidal folds, which interestingly, persist even after complete removal of the hemangioma [28]. Less frequently reported symptoms include double vision, lid swelling, and lump sensation. Amaurosis is an unusual symptom associated with several intraconal and extraconal orbital lesions, probably caused by optic nerve ischemia as this is compressed by the retrobulbar mass [29].
Fig. 6. Histopathological images of orbital cavernous venous malformation: Case 3. A). encapsulated lesion composed of dilated, cavernous vascular spaces lined by a single layer of endothelial cells and separated by connective tissue stroma. Budding-off of capillary channels could be seen ( $\mathrm{H}$ and $\mathrm{E}$ staining, $x 10) . B$ ). Large, anastomosing vascular spaces, filled with blood and separated by fibrous stroma. Vascular spaces showed smooth muscle walls with different thicknesses, ranging from one to 10 layers for the same blood vessel

( $\mathrm{H}$ and $\mathrm{E}$ staining, $\mathrm{x} 5$ ).

Usually, CT and MRI reveal a well circumscribed round or ovoid orbital mass (fig. 2). CT shows homogeneous soft tissue density, and may also identify small calcifications or phleboliths [30,43]. MRI shows isointense T1 signal, bright T2 signal, dark internal septations and a dark circumferential rim that represents a fibrous pseudocapsule $[27,30,31]$. On contrast injection, the lesion shows progressive filling and becomes homogenous. This pattern is considered to be characteristic of cavernous hemangioma [28].

The differential diagnosis of well circumscribed orbital lesions includes schwannoma, fibrous histiocytoma, hemangiopericytoma as well as metastatic lesions, but cavernous hemangioma is the most often encountered benign orbital lesion [28, 32].

Histopathological examination of a cavernous hemangioma reveals a benign vascular malformation characterized by a well-defined capsule and numerous large dilated vascular channels lined by endothelial cells with an intervening fibrous interstitium [16, 25, 33].

However, some authors made immunohistochemical investigations and demonstrated that the vascular channels reacted strongly with the traditional blood vessel endothelial markers CD31 and CD34, but they were negative for D2-40, separating them from lymphangiomas [2].

Inflammatory cells and macrophages may be present, and foci of lymphocytes are absent or sparse. But there are some atypical clinical cases where there was an obvious infiltration of inflammatory cells within the interstitium of the lesion [34]. The vascular lumen is filled with blood and there could be regions with intralesional thrombosis, reflecting vascular stasis or slow flow. The stromal structure shows perivascular hypercellularity or hyperplastic elements related to neovascular activity [14].

In our cases, we identified a mixture of venous muscular channels and of capillary structures. All these structures were separated by thick strands of connective tissue. As other authors reported [2] we identified in the walls of large vascular channels variable multilaminar smooth muscle- 
like bundles under the endothelium, the image being most closely to dysplastic veins. So, we concluded that the socalled orbital cavernous hemangioma is rather a cavernous venous malformation. However, Osaki et al. (2013) demonstrated by immunohistochemical staining that multilaminar vascular walls stained positive with Smooth Muscle Actine (SMA), but negative with desmin, and these features indicated a myofibroblastic differentiation rather than smooth muscle differentiation [2]. Growth of the lesion may occur intrinsically by the budding-off of capillary channels from cavernous spaces into the interstitium [17]. In our histological sections, we also identified closely packed capillary vessels in the interstitium. Nagasaka et al. (2007) reported that VEGF and flk-1 immunostaining were positive in endothelial cells in their nine specimens and concluded that both VEGF and its receptor flk-1 are important in the growth of orbital cavernous hemangioma [35]. There is a discordant expression of proliferative markers. PCNA and BCl-2 show positivity in the absence of Mib-1 and this fact demonstrates its low proliferative potential [36]. As the vascular network advances towards the neighbouring tissue, it induces a fibrous capsule at the interface. In this process of expansion, the lesion can displace, compress, or incorporate surrounding structures. In the anterior and middle orbit, the relatively mobile muscles, nerves, vessels can accommodate that slow expansion by moving aside and visual impairment occurs only with large lesions. By contrast, in the orbital apex, there is no room for displacement and the vessels and the nerves are tightly compacted and directly apposed [37].

Due to the fact that orbital cavernous venous malformation is benign and has a slow growth, in asymptomatic cases it is recommended that patients should be followed with visual field and imaging testing. Surgery should be considered in symptomatic patients and even if the surgical dissection is quite easy and bloodless it should be planed carefully according to the anatomical location of the lesion and its relationship with the orbital structures and facial sinuses identified anatomoradiological studies [38, 39]. In this regard, medicine faces ethical and legal issues, and surgery should also be planed according to patient, respecting his personal values [4042].

Anterior orbitotomy is general used for the excision of both extraconal and intraconal lesions, not involving the orbital apex [37]. The transconjunctival approach can be successfully used for small tumors located laterally or medially to the eyeball $[25,43]$. We preferred using this approach in twelve cases because it provides excellent exposure of the orbit, leaving no visible scar and possessing a lower risk of complications. However, in two cases we decided to use a subcilliary incision due to the lesions' anterior and inferior position. In such cases, it is important to use blunt dissection to free the tumor from the surrounding attachments.

Additionally, in large lesions, lateral canthotomy may be necessary for better exposure. The cryoprobe is an ideal tool for orbital cavernous venous malformation extirpation, and is reported to have good results in reducing intraoperative capsular rupture and bleeding $[24,26,44]$. A disadvantage of the method is that adjacent structures may also be frozen [44]. Complications reported with the anterior approach are lid hematoma, mydriasis, loss of vision from direct optic nerve damage, arterial occlusion or entropion/ectropion [15]. In our patients, no serious or permanent complications were observed during or after the operation and good follow-up results were achieved in terms of proptosis and diplopia improvement. Due to the benign nature of the lesion, there was no recurrence six months following excision.

Recently, endoscopic transnasal approach has gained popularity for the management of orbital cavernous venous malformation located in the medial or inferior orbital compartment $[45,46]$. Access to the posterior medial orbit can be gained transnasally through the ethmoid and sphenoid sinuses. The endonasal endoscopic approach also permits decompression of the medial wall of the orbit. However, the removal of larger lesions is limited with this approach. The transantral approach through the maxillary sinus allows greater access to the floor of the posterior orbit and facilitates removal of larger lesions [17,47,4853]. In addition to the transnasal endoscopic approach, Caldwell-Luc-type procedures have also been used to reach orbital lesions [25]. In our opinion such a traumatic approach is not necessary, the transconjuctival procedure offering a good enough approach for safe removal of the orbital haemangioma.

\section{Conclusions}

Our series of cases demonstrated that orbital cavernous hemangiomas express clinical and imaging features of a benign lesion which occurs usually in adult females. Surgery was recommended in the presence of clinical manifestations (exophthalmos, proptosis, and diplopia). Having to deal with extraconal lesions, we successfully used anterior orbitotomy, mainly the transconjuctival approach, with no complications or recurrences after a six-month follow-up period. Histologically, all lesions revealed medium-sized vascular channels with mature endothelium lining and variable smooth muscle-like layers under the endothelium, an image being most closely to dysplastic veins. So, we concluded that the so-called orbital cavernous hemangioma is rather a cavernous venous malformation. We also identified nests of microcapillary networks in the interstitium of these lesions and considered these features as the proof of their slow, but progressive growth.

\section{References}

1.EL SAQUI, A., AGGOURI,M., BENZAGMOUT, M., CHAKOUR.,K, EL FAIZ CHAOUI,M., Pan Afr Med J, 26, 2017, p.131.

2.OSAKI, T.H., J AKOBIEC,F.A., MENDOZA,P.R., LEE,Y., FAY,A.M., Ophthal Plast Reconstr Surg,29, nr.3, 2013, p.183-195.

3.SKARICA, R., ZDILAR, B., RASIC,D., HARAPIN,M., ANDABAKA, T.,FUDURI/E,J ., ZADRO,Z., Acta Chir Croat, 12, nr.1, 2015, p.51-54. 4.ZAUBERMANN, L., FEINSOLD, M., Acta Ophthalmol, 48, 1979, p. 929933.

5.EVAGELIDOU, E., TSANO, E., ASPROUDIS, I., GOREZIS, S., ASPIOTIS, M., PESCHOS, D., SIAMOPOULOU, A., Cases J , 2, .2009, p. 2:6912. 6.HINGANU, D., HINGANU, M.V., MIHALCEANU, E., CALIN, A.M., PANGAL, A., COSTACHESCU, G., ROMILA, A. Rev. Chim. (Bucharest), 69, no.3, 2018, p. 714-716.

7.RAMA, A., KAVITA, D., PANKAJ, S., NARULA, M.K., RAJ IV,G.,Indian J Radiol Imaging, 18, nr.4, 2008, p.310-312.

8.KOSAKA, M., MIZOGUCHI,T., MATSUNAGA,K., FU, R., NAKAO,Y., J Craniofac Surg, 17, nr.6, 2006, p.125-128.

9.POPESCU, E.,FORNA,D.A., EARAR,K.., et al.,Mat. Plast., 54, no.2, 2017, p. 390-392

10.ASAFTEI, I.V., SANDU, I.G., BIRSA,L.M., etal., Rev.Chim.(Bucharest), 66, no.3, 2015, p. 336-341

11.ANTOHE, M.E., AGOP FORNA, D., DASCALU,C.G., Rev.Chim. (Bucharest), 69, no. 2, 2018, p.521-524.

12.WANG, X., YAN, J., Eye Sci, 26, nr.1, 2011, p. 48-51.

13.SHIELDS,J ., HOGAN,R., SHIELDS,C., EAGLA,R., KENNEDY,R., SINGH,A., Br J Ophthalmol, 84, nr.8, 2000, p. 928.

14.RUCHMAN, M.C., FLANAGAN, J., Ophthalmology, 90, nr.11, 1983, p.1328-1336. 
15.ROOTMAN,D.B., HERAN, M.K., ROOTMAN,J., WHITE,V.A., LUEMSAMRAN,P., YUCEL, Y.H., Br J Ophthalmol, 98, nr. 7, 2014, p.880888.

16.ANSARI, S.A., MAFEE,M.F., Neuroimag Clin North America, 15, nr.1, 2005, p.137-158.

17.HARRIS,G.J ., J AKOBIEC,F.A., J Neurosurg, 51, nr.2,1979, p. 219-228. 18.MCNAB,A.A.,W RIGHT, J.E.,Aust New Zealand J Ophthalmol,17, nr.4, 1989,p.337- 345.

19.SAVOIARDO,M.,STRADA,L., PASSERINI, A., AJ NR Am J Neuroradiol,4, nr.3, 1983, p.741-744.

20.JAYARAM, A., LISSNER, G.S.,COHEN, L.M., KARAGIANIS, A.G., Ophthal Plast Reconstr Surg, 31, nr.3, 2015, p.187-190.

21.MCNAB,A.A., TAN, J.S., XIE,J ., SELVA,D., HARDY,T.G.,STARTE,J ., O'DONNELL, B., Ophtal Plast Reconstr Surg, 31, nr.2, 2015, p.89-93. 22.J OHNSON, T.E., NASR,A.M., NALBANDIAN,R.M., CAPPELEN-SMITH,J., Am J Ophthalmol, 110, nr.2, 1990, p.153-159.

23.CHANG, E.L., RUBIN, P.A.,Ophthalmology, 109, 2002, p.537-541.

24.SCHEUERLE,A.F., STEINER,H.H., KOLLING,G., KUNZE,S., ASCHOFF,A., Am J Ophthalmol, 138, 2004, p.237-244.

25.CALANDRIELLO,L.,GRIMALDI,G., PETRONE,G., RIGANTE,M., PETRONI,S., RISO,M., SAVINO,G., Surv Ophtalmol, 62, nr.4, 2017, p.393403.

26.HSU, C.H., HSU, W.M., J Exp Clin Med,3, nr.6, 2011, p.278-282. 27.BILANIUK, L.T., Radiol Clin North America,37, nr. 1, 1999, p.169183.

28.GUNDUZ, K., KARCIOGLU,Z.A.Vascular tumors. In: Karcioglu ZA (ed). Orbital tumors: diagnosis and treatment, Springer, New York, 2015, p.155-158.

29.OTTO,C.S., COPPIT,G.L., MAZZOLI,R.A.,Ophthalmology,110, nr.2, 2003, p.322-326.

30.KHAN,S.N., SEPAHDARI,A.R., Saudi] Ophtalmol, 26, nr.4, 2012, p.373383.

31.THORN-KANY,M., ARRUE,P., DELISLE,M.B., LACROIX,F., LAGARRIGUE, ., MANELFE,C., J ( Neuroradiol, 26, nr.2, p. 79-86. 32.SCUTARIU MM, HINGANU D, MACOVEI G, HINGANU MV. Romanian Journal Of Oral Rehabilitation, 10, no.4, 2018, p. 186-192.

33.SMOKER,W.R.K., GENTRY,L.R., YEE,N.K., REEDE,D.L., NERAD,J .A., Radio Graphics, 28, nr.1, 2008, p. 185-204.

34.YAN, ., LI,Y., J Craniofac Surg, 25, nr.4, 2014, p.348-349.

35.NAGASAKA,M., NAGANUMA,H., SATOH,R., Neurol Med Chir (Tokyo), 47, nr.1, 2007, p.5-10.
36.GUPTA,A., PRABHAKARAN,V.C., DODD,T., DAVIS,G., SELVA,D., Orbit, 31, nr.6, 2012, p. 386-389.

37.HARRIS,G.J., Am J Ophtalmol, 150, nr.6, 2010, p.764-773.

38.COBZEANU, M.D., BALDEA, V., BALDEA, M C , VONICA, P S COBZEANU, B. M., Rom J Morphol Embryol, 55, 2014, p.1099-1104.

39.ROMANEC, C., PACURAR, M., DECUSARA, M., SCUTARIU, M.M., et al. Rev.Chim. (Bucharest), 69, no. 4, 2018, p. 1002-1005.

40.CRACIUN, P., ASTARASTOAE, V., TURLIUC, S., VICOL, M.C., Revista de Cercetare si Interventie Sociala, 42, 2013, p. 310-319.

41.CRACIUN, P., VICOL, M.C., TURLIUC, S., ASTARASTOAE, V., Romanian J ournal of Bioethics, 10, 2012, p. 92-101.

42.DEBITA, M., MUSAT, C., MEREUTA, E., et al., Rev.Chim.(Bucharest), 68, no.9, 2017, p. 2048-2051

43.ROSEN,N., PRIEL,A., SIMON,G.J ., ROSNER, M., Acta Ophthalmol, 88, nr.6, 2010, p.675-680.

44.BOARI,N., GAGLIARDI,F., CASTELAZZI,P., MORTINI,P., Acta Neurochir, 153, nr.3, 2011, p.491-498.

45.BLEIER,B.S., CASTELNUOVO,P., BATTAGLIA, P., TURRI-ZANONI,M., DALLAN,I., METSON,R., SEDAGHAT,A.R., STEFKO,S.T., GARDNER,P.A., SNYDERMAN,C.H., NOGUEIRA, J.F., RAMAKRISHNAN,V.R., MUSCATELLO,L., LENZI,R., FREITAG,S., Int Forum Allergy Rhinol, 6, nr.2, 2016, p.156-161.

46.TSIRBAS,A., KARIM,M., CLOSE, L., Ophthal Plast Reconstr Surg, 21, no.4,2005, p.271-275.

47.J UMANCA, D.,GALUSCAN,A., PODARIU,A.C., et al, Rev.Chim. (Bucharest), 65, no.12, 2014, p. 336-341.

48.EARAR, K., BUDACU,C., HABA,D., COVRIG, V., MIHAI, C., ROMANIAN JOURNAL OF ORAL REHABILITATION, 10(3), 2018, p.116124

49.SCUTARIU M.M., CIURCANU O.E., AGOP FORNA D., et al., MEDICAL SURGICAL JOURNAL, 120, no.4, 2016, p.926

50.BUDACU, C., NEMTOI, A.,MIHAI, C., Mat.Plast, 54, no. 4, 2017, p.773

51.HABA, D., BUDACU, C., MIHAI, C., Rev.Chim.(Bucharest), 68, no.12 ,2017, p.2829.

52.NITESCU, D., MIHAI, C., OANTA, C., Rev.Chim.(Bucharest), 68, no.3, 2017, p. 549

53.BARTOK F.L., FORNA N.C., ROMANIAN J OURNAL OF ORAL REHABILITATION, 67, no. 9, 2016, p.1722.

Manuscript received: 17.07 .2018 